\title{
Preparation and magnetic properties of $\mathrm{Al}_{2} \mathrm{O}_{3}$-coated acicular $\alpha$-Fe particles
}

\author{
C.H. Lin ${ }^{a}$, , T.S. Chin ${ }^{a}$, P.C. Kuo ${ }^{b}$, S.C. Chen ${ }^{b}$, C.S. Shih ${ }^{b}$ \\ ${ }^{a}$ Department of Materials Science and Engineering, National Tsing Hua University, Hsinchu, Taiwan, ROC \\ ${ }^{\mathrm{b}}$ Institute of Materials Science and Engineering, National Taiwan University, Taipei, Taiwan, ROC
}

Received 19 December 1994; accepted 29 June 1995

\begin{abstract}
Al-modified acicular $\alpha$-Fe particles were produced using the chemical precipitation method by adding Al ion on the surface of $\alpha-\mathrm{FeOOH}$. This was followed by air oxidation, dehydration, and hydrogen reduction processes. Various dehydration, reduction temperatures and times were also studied. The addition of $\mathrm{Al}$ ion impeded the interparticle sintering, spherization, and grain growth processes which were found to occur during dehydration and reduction. Consequently, ${ }_{i} \mathrm{H}_{\mathrm{c}}$ increased with the addition of $\mathrm{Al}$ ion, reached a maximum at $3 \mathrm{wt} . \% \mathrm{Al}$ and later decreased again. The addition of $\mathrm{Al}$ ion always decreased the $\sigma$ value of $\alpha-\mathrm{Fe}$ particles. The addition of $\mathrm{Al}$ ion prevented the $\alpha$-Fe particles from deteriorating. At room temperature, 3 and $1.5 \mathrm{wt} . \%$ of $\mathrm{Al}$ ions would be required, respectively, for stabilizing the $\sigma$ and ${ }_{i} \mathrm{H}_{c}$ values of $\alpha$-Fe particles. At elevated temperature, ${ }_{i} \mathrm{H}_{c}$ would deteriorate faster than the $\sigma$ value.
\end{abstract}

Keywords: Magnetic properties, $\alpha$-Fe particles; Alumina

\section{Introduction}

Acicular $\alpha$-Fe particles are utilized extensively in high quality magnetic recording media. Acicular $\alpha$-Fe particles can be produced from the dehydration of acicular $\alpha-\mathrm{FeOOH}$ to $\alpha-\mathrm{Fc}_{2} \mathrm{O}_{3}$, along with a subsequent reduction of $\alpha-\mathrm{Fe}_{2} \mathrm{O}_{3}$. The $\alpha-\mathrm{Fe}_{2} \mathrm{O}_{3}$ particle surface must be modified not only to maintain the particle in its acicular shape during dehydration and reduction, but also to prevent $\alpha-\mathrm{Fe}$ particles from corroding. A thin layer of $\mathrm{SiO}_{2}$ [1,2], borates [3], or $\mathrm{Fe}_{3} \mathrm{O}_{4}$ [4] has been previously coated on the $\alpha-\mathrm{FeOOH}$ particle surface. Al ion was added in the range between 0 and $24 \mathrm{wt} . \%$ during our previous investigation [5]. In that work, $\mathrm{Al}$ ion was observed to be an effective diffusion barrier capable of maintaining $\alpha$-Fe particles in their acicular shape during dehydration and reduction. However, magnetization of these heavily doped $\alpha-F e$ particles deteriorated.

\footnotetext{
* Corresponding author.
}

More extensive research has been undertaken in this study, involving the effect of $\mathrm{Al}$ ion between 0 and $3 \mathrm{wt} . \%$ on the magnetic properties and environmental stability of $\alpha-\mathrm{Fe}$ particles. The effects of preparation processes, e.g., precipitation, dehydration, and reductions on the magnetic properties of $\alpha-\mathrm{Fe}$ particles, were also studied.

\section{Experimental}

An $\alpha-\mathrm{FeOOH}$ suspension, which was obtained by chemical precipitation from $\mathrm{FeCl}_{2}$ solution and subsequent air oxidation, was modified by the addition of $\mathrm{Al}$ ion from $\mathrm{Al}_{2}\left(\mathrm{SO}_{4}\right)_{3}$ solution [5].

In order to prepare fine $\mathrm{Al}$ modified $\alpha-\mathrm{FeOOH}$ particles for subsequent dehydration and reduction, $\alpha-$ $\mathrm{FeOOH}$ was prepared using $0.1 \mathrm{M} \mathrm{FeCl}$, with neutralization by an equal volume of $0.5 \mathrm{M} \mathrm{NaOH}$ solution, and precipitation of $\mathrm{Al}$ ion at $\mathrm{pH} 9$.

Al modified $\alpha$-FeOOH was dehydrated in open air at $300-800^{\circ} \mathrm{C}$, so that $\mathrm{Al}(\mathrm{OH})_{3}$ and $\mathrm{FeOOH}$ be- 


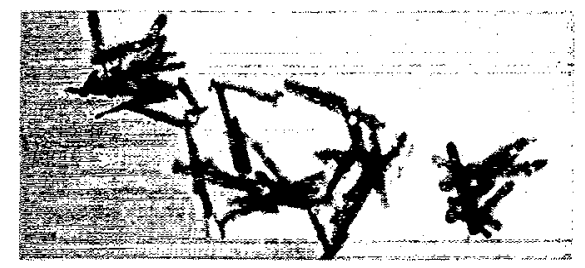

(a)

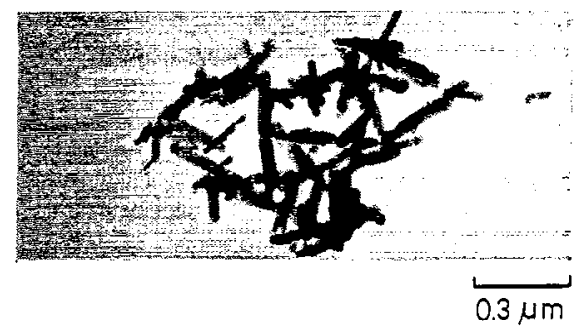

(b)

Fig. 1. $\alpha-\mathrm{Fe}_{2} \mathrm{O}_{3}$ dehydrated at various tempcraturcs for $1 \mathrm{~h}$ : (a) $400^{\circ} \mathrm{C}$; (b) $600^{\circ} \mathrm{C}$.

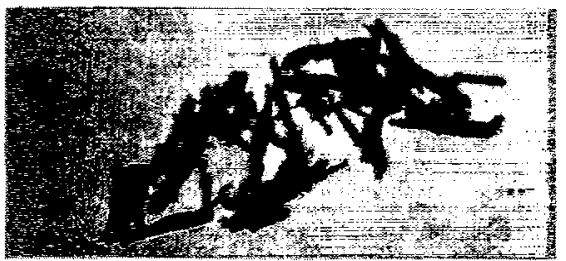

(a)

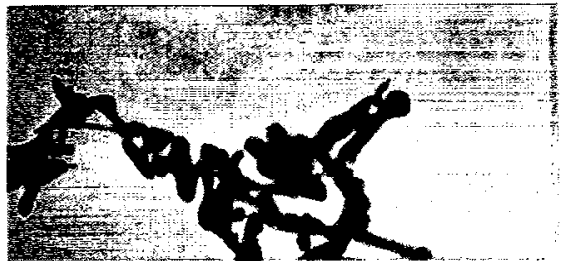

(b)

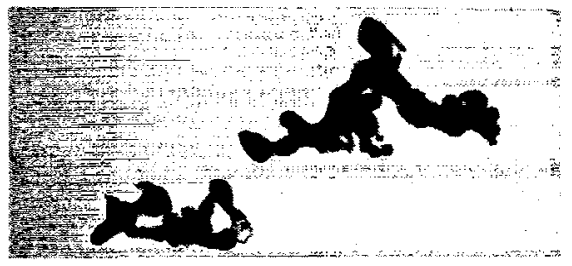

(c)

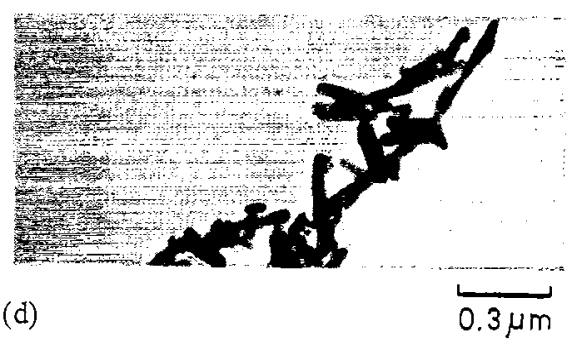

Fig. 2, $\alpha-\mathrm{Fe}$ particles reduced at various temperaturcs for $2 \mathrm{~h}$ : (a) $500{ }^{\circ} \mathrm{C}, 1.5 \mathrm{wt} \%$; (b) $520{ }^{\circ} \mathrm{C}, 1.5 \mathrm{wt} \%$; (c) $540{ }^{\circ} \mathrm{C}, 1.5 \mathrm{wt} \%$; (d) $520^{\circ} \mathrm{C}, 3 \mathrm{wt} . \%$.

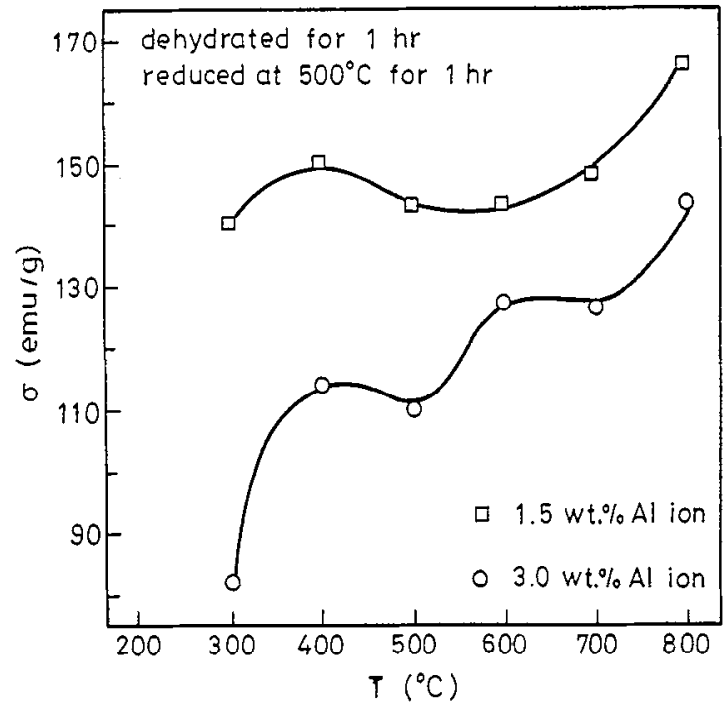

Fig. 3. $\sigma$ values of $\alpha$-Fe particles for various dehydration temperatures.

came $\gamma-\mathrm{Al}_{2} \mathrm{O}_{3}$ and $\alpha-\mathrm{Fe}_{2} \mathrm{O}_{3}$, respectively. $\alpha-\mathrm{Fe}_{2} \mathrm{O}_{3}$ was reduced in hydrogen at 500,520 and $540{ }^{\circ} \mathrm{C}$, respectively, for $1-2.5 \mathrm{~h}$ so as to produce $\mathrm{Al}_{2} \mathrm{O}_{3}$ modified $\alpha$-Fe particles.

The environmental stability of the Al-modified $\alpha-\mathrm{Fe}$ particles was tested by placing the particles in the following different environments: (1) in open air at room temperature for a few days to several weeks; (2) at elevated temperatures ranging from 25 to $200^{\circ} \mathrm{C}$ for $1 \mathrm{~h}$; and (3) in a humid environment with $95 \%$ relative humidity at $45^{\circ} \mathrm{C}$ for $1-3$ days.

The composition, shape, structure, and magnetic properties of the $\mathrm{Al}$ modified $\alpha-\mathrm{Fe}$ particles were measured for different production procedures and various environments.

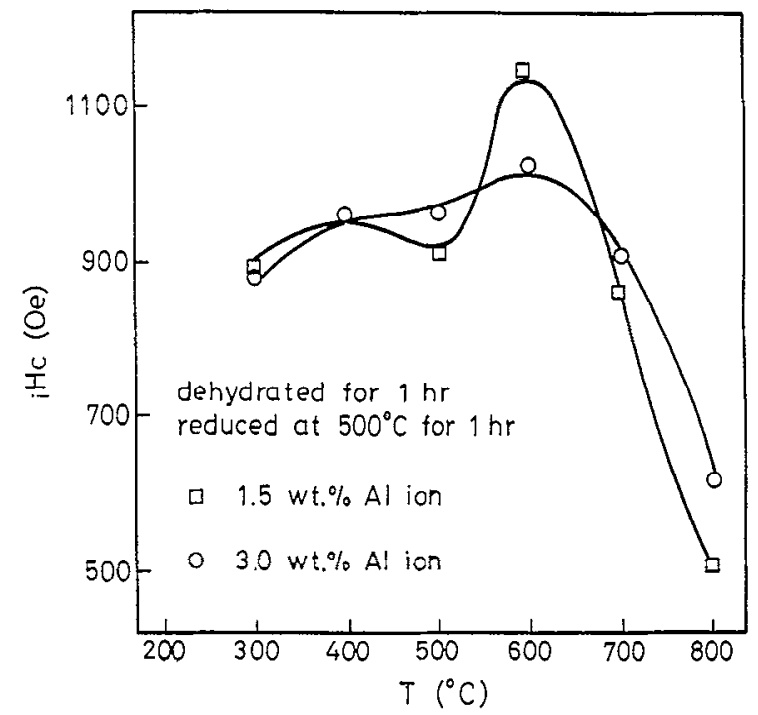

Fig. 4. ${ }_{\mathrm{i}} \mathrm{H}_{\mathrm{c}}$ values of $\alpha$-Fe particles for various dehydration temperatures. 


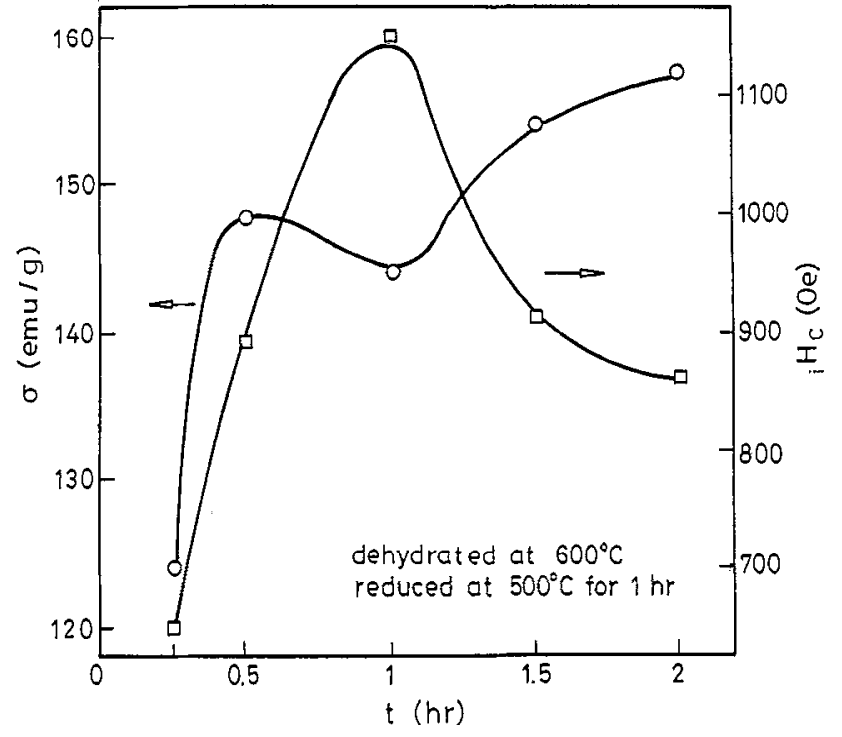

Fig. 5. $\sigma$ and ${ }_{i} \mathrm{H}_{c}$ values of $\alpha-\mathrm{Fe}$ particles for various dehydration times.

\section{Results and discussion}

The lengths of acicular $\alpha$-FeOOH particles, as observed from electron micrographs, were around 0.1 , $0.15,0.2$, and $0.25 \mu \mathrm{m}$ from $0.1 \mathrm{M}, 0.15 \mathrm{M}, 0.2 \mathrm{M}$, and $0.25 \mathrm{M} \mathrm{FeCl}_{2}$ solution, respectively. The aspect ratio is around 10 . An increase in the oxidation temperature from 30 to $50^{\circ} \mathrm{C}$ would lead towards an increase in the $\alpha-\mathrm{FeOOH}$ particle length from 0.25 to $0.5 \mu \mathrm{m}$.

No spherization and grain growth were found in the $400{ }^{\circ} \mathrm{C}$ treated sample, as shown in Fig. 1. A slight amount of grain growth was also found in the $600^{\circ} \mathrm{C}$ treated $\alpha-\mathrm{Fe}_{2} \mathrm{O}_{3}$ sample. When preparing $\alpha-\mathrm{Fe}_{2} \mathrm{O}_{3}$ for hydrogen reduction, complete dehydration of $\mathrm{Fe}_{2} \mathrm{O}_{3}$ and $\mathrm{Al}_{2} \mathrm{O}_{3}$ could be achieved by selecting the dehydration temperature to be $600{ }^{\circ} \mathrm{C}$.

Extensive spherization and grain growth are found (Fig. 2(a)-2(c)) to occur for $\alpha$-Fe particles containing

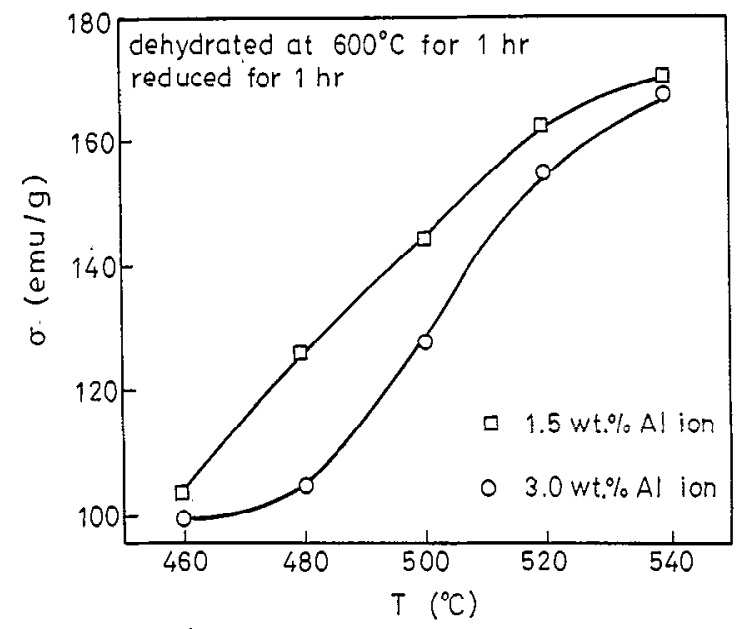

Fig. 6. $\sigma$ values of $\alpha$-Fe particles for various reduction temperatures.

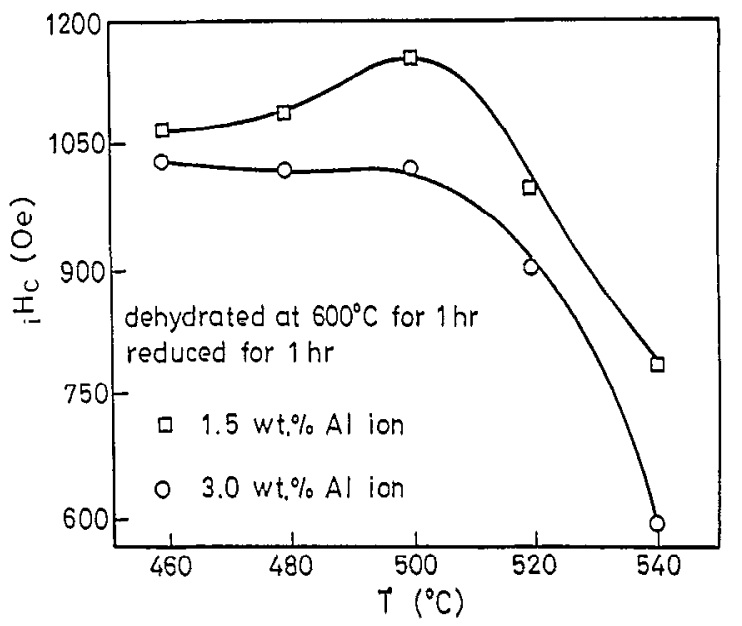

Fig. 7. ${ }_{i} \mathrm{H}_{\mathrm{c}}$ values of $\alpha$-Fe particles for various reduction temperatures.

$1.5 \mathrm{wt} . \% \mathrm{Al}$, when the reduction temperature increased from 500 to $540{ }^{\circ} \mathrm{C}$. A comparison of Fig. 2(b) with 2 (d) reveals that less spherization and grain growth occurred when the $\mathrm{Al}$ ion content increased from 1.5 to 3 wt. \%. Moreover, the $\mathrm{Al}_{2} \mathrm{O}_{3}$ coating layer could effectively reduce the spherization and grain growth during reduction.

As expected, Fig. 3 shows that a higher dehydration temperaturc has a higher $\sigma$ value, and in addition, $\alpha$-Fe containing $1.5 \mathrm{wt} \% \mathrm{Al}$ ion has a higher $\sigma$ value than $\alpha-\mathrm{Fe}$ containing $3 \mathrm{wt} . \% \mathrm{Al}$ ion. The ${ }_{\mathrm{i}} \mathrm{H}_{\mathrm{c}}$ value of $\alpha-\mathrm{Fe}$, as Fig. 4 shows, reaches a maximum for the sample dehydrated at $600^{\circ} \mathrm{C}$ for $1 \mathrm{~h}$. In particular, $\alpha-\mathrm{Fe}$ containing $1.5 \mathrm{wt} . \% \mathrm{Al}$ ion has a sharp maximum. Next, various dehydration times were applied at the dehydration temperature of $600^{\circ} \mathrm{C}$, which has the highest $\sigma$ value. The higher $\sigma$ values occur for longer dehydration times, as shown in Fig. 5 . The ${ }_{i} \mathrm{H}_{c}$ value reaches a maximum at $1 \mathrm{~h}$. The shape of the ${ }_{\mathrm{i}} \mathrm{H}_{\mathrm{c}}$ vs. dehydra-

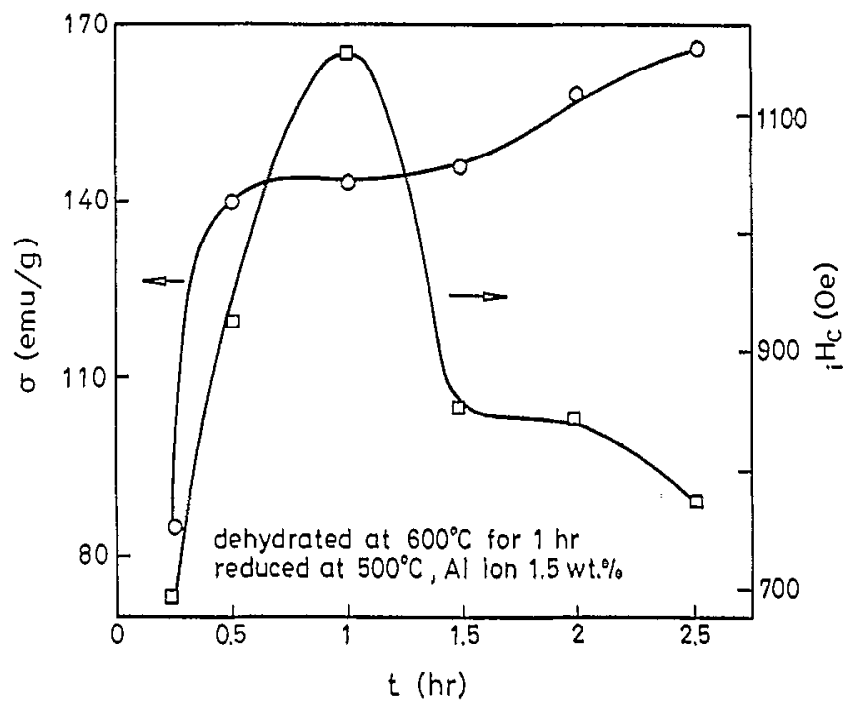

Fig, 8. $\sigma$ and ${ }_{\mathrm{i}} \mathrm{H}_{\mathrm{c}}$ values of $\alpha$-Fe particles for various reduction times. 


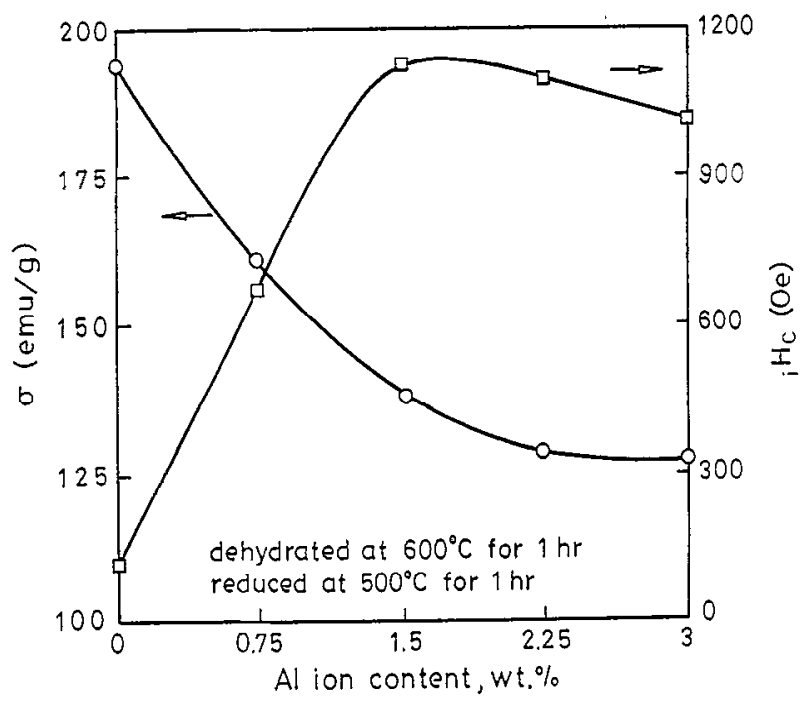

Fig. 9. $\sigma$ and ${ }_{\mathrm{i}} \mathrm{H}_{\mathrm{c}}$ values of $\alpha-\mathrm{Fe}$ particles for various $\mathrm{Al}$ ion contents.

tion time curve is the same as that of the ${ }_{i} \mathrm{H}_{c}$ vs. dehydration temperature curve.

As expected, Fig. 6 shows that a higher reduction temperature has a higher $\sigma$ value, and a lower $\mathrm{Al}$ ion content $(1.5$ wt. $\%)$ has a higher $\sigma$ value. The ${ }_{i} \mathrm{H}_{c}$ value of $\alpha-\mathrm{Fe}$, as shown in Fig. 7, reaches a maximum for the $1.5 \mathrm{wt} \% \mathrm{Al}$ ion sample reduced at $500^{\circ} \mathrm{C}$ for $1 \mathrm{~h}$. For the $3 \mathrm{wt} . \%$ sample, the $\mathrm{H}_{\mathrm{c}}$ value of $\alpha-\mathrm{Fe}$ decreases with an increase in the reduction temperature. The ${ }_{i} \mathrm{H}_{c}$ value sharply decreases when the reduction temperature is higher than $520^{\circ} \mathrm{C}$. As shown in Fig. 8, the $\sigma$ value of the $1.5 \mathrm{wt} \%$ sample sharply increases with the reduction time at $500^{\circ} \mathrm{C}$. Later, $\sigma$ gradually levels off as the reduction time extends longer than $30 \mathrm{~min}$. The ${ }_{\mathrm{i}} \mathrm{H}_{\mathrm{c}}$ value of the $1.5 \mathrm{wt} . \%$ sample sharply increases with the reduction time at $500{ }^{\circ} \mathrm{C}$, and reaches its maximum at $1 \mathrm{~h}$. The ${ }_{\mathrm{i}} \mathrm{H}_{\mathrm{c}}$ value sharply decreases for reduction times longer than $1 \mathrm{~h}$. Additionally, this value levels

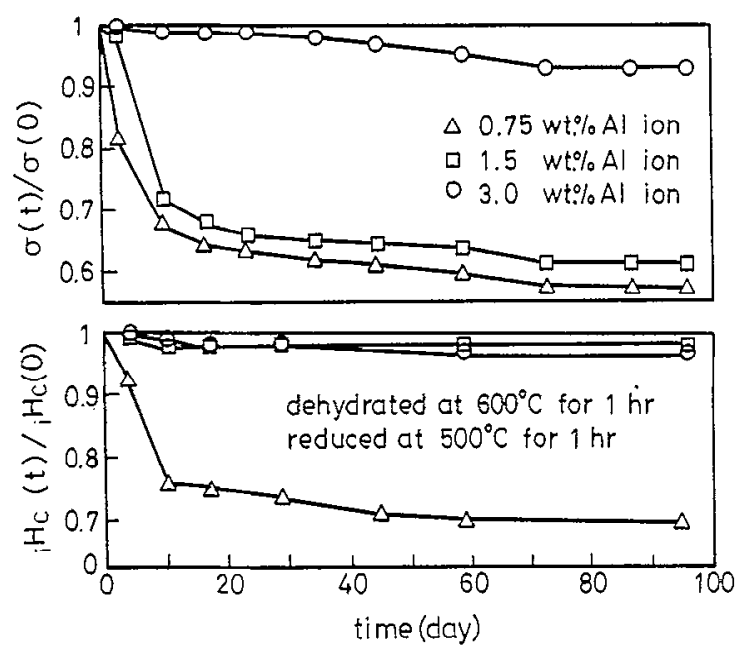

Fig. 10. $\sigma$ and ${ }_{i} H_{c}$ values of $\alpha-F e$ particles for various exposure times.

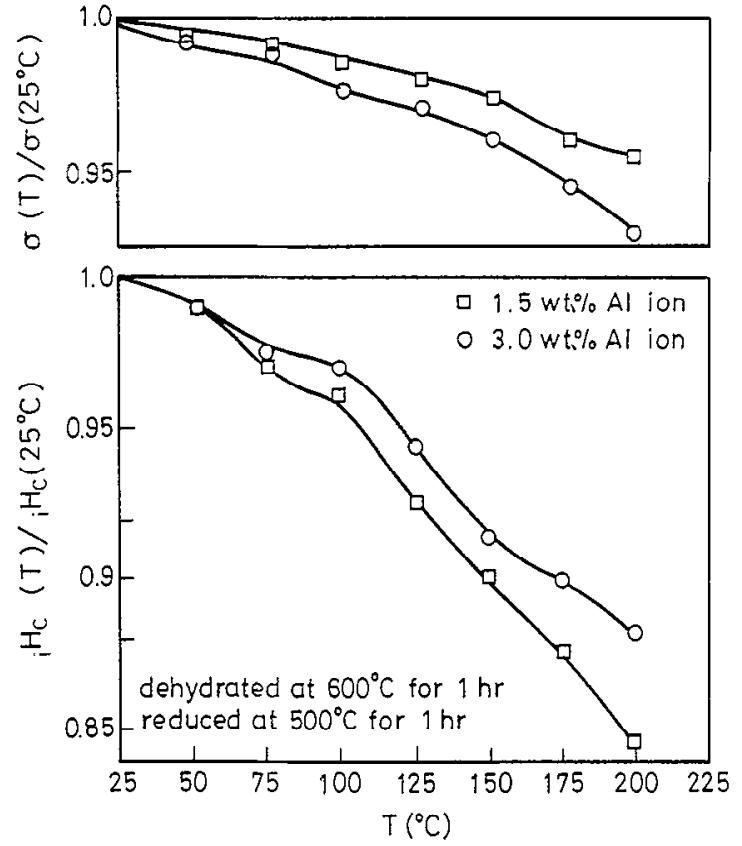

Fig. 11. $\sigma$ and ${ }_{i} H_{c}$ values of $\alpha$-Fe particles for various exposure temperatures.

off if the reduction time extends longer than $1.5 \mathrm{~h}$. The magnetic properties of $\alpha$-Fe samples without $\mathrm{Al}$ ion are not shown in Figs. 3-7 because these uncoated samples deteriorated away before their magnetic properties could be measured.

As shown in Fig. 9, the addition of $\mathrm{Al}$ ion always decreases the $\sigma$ value of $\alpha$-Fe particles from the beginning. With the addition of $\mathrm{Al}$ ion the value of ${ }_{i} \mathrm{H}_{\mathrm{c}}$ increases, reaches a maximum, and then decreases again. The reason for ${ }_{i} \mathrm{H}_{c}$ increasing is that the $\mathrm{Al}_{2} \mathrm{O}_{3}$ coating layer as indicated in Fig. 2 impeded the excessive interparticle sintering, spherization, and grain growth. The reason for ${ }_{i} \mathrm{H}_{\mathrm{c}}$ decreasing is that it may react with $\mathrm{Fe}_{2} \mathrm{O}_{3}$ when forming a new compound incapable of being reduced during reduction reaction. The optimum condition for preparing $\alpha-\mathrm{Fe}$ particle is as follows: dehydration at $600^{\circ} \mathrm{C}$ for $1 \mathrm{~h}$, reduction at $500^{\circ} \mathrm{C}$ for $1 \mathrm{~h}, \mathrm{Al}$ ion content $1.5 \mathrm{wt} . \%$. Under this condition, $\alpha$-Fe particles with magnetic properties of $\sigma=143.5 \mathrm{emu} \mathrm{g}^{-1}$ and ${ }_{\mathrm{i}} \mathrm{H}_{\mathrm{c}}=1150$ Oe can be obtained.

The Al-modified $\alpha$-Fe particles begin deteriorating when exposed to the open atmosphere. Fig. 10 shows that for the $0.75 \mathrm{wt} . \%$ and $1.5 \mathrm{wt} . \%$ samples, $\sigma(t)$ reduced to $65 \%$ of its original value after 20 days of exposure. For the $3 \mathrm{wt} \%$ sample, the $\sigma$ value decreases only slightly after 20 days of exposure, and the $\sigma(t)$ value reduces only $7 \%$ after 96 days of exposure. Fig. 10 shows that for the $0.75 \mathrm{wt} . \%$ sample, the value of ${ }_{1} \mathrm{H}_{\mathrm{c}}$ reduces $24 \%$ after 10 days of exposure. For the 1.5 and $3 \mathrm{wt} . \%$ samples, the decrease in ${ }_{i} \mathrm{H}_{c}$ is only slight after 96 days of exposure. We believe that the $\mathrm{Al}_{2} \mathrm{O}_{3}$ coating layer can prevent the $\alpha$-Fe particles from direct contact with air. There- 
fore, the $\mathrm{Al}$ ion content must be higher than $1.5 \mathrm{wt} . \%$ so that the coating layer is sufficiently thick to provide effective protection of $\alpha$-Fe particles from oxidation.

Both $\sigma(t) / \sigma(0)$ and ${ }_{\mathrm{i}} \mathrm{H}_{c}(t) / \mathrm{H}_{\mathrm{i}} \mathrm{H}_{c}(0)$ in Fig. 11 decrease with the heating temperature. A higher temperature deteriorated ${ }_{i} \mathrm{H}_{\mathrm{c}}$ more than $\sigma$.

\section{Conclusions}

Extensive spherization and grain growth were found to occur during reduction of acicular $\alpha-\mathrm{Fe}_{2} \mathrm{O}_{3}$ particles to $\alpha-\mathrm{Fe}$ particles at $500^{\circ} \mathrm{C}$. A higher reduction temperature, $540{ }^{\circ} \mathrm{C}$, made it worse. $3 \mathrm{wt} . \%$ of $\mathrm{Al}$ was observed to be more effective than $1.5 \mathrm{wt} . \%$ of $\mathrm{Al}$ in reducing grain growth during reduction. However, even those samples were sintered.

The addition of $\mathrm{Al}$ ion always decreases the $\sigma$ value of $\alpha$-particles. The addition of $\mathrm{Al}$ ion increases the ${ }_{\mathrm{i}} \mathrm{H}_{\mathrm{c}}$ value, which reaches a maximum and then decreases again.
The addition of $\mathrm{Al}$ ion increases the stability of $\alpha$-Fe. At room temperature $3 \mathrm{wt} . \%$ is required for stabilizing the $\sigma$ value of $\alpha$-Fe particles, while only $1.5 \mathrm{wt} . \%$ is required for stabilizing the $\mathrm{H}_{\mathrm{c}}$ value of $\alpha$-Fe particles. At elevated temperature, ${ }_{i} \mathrm{H}_{\mathrm{c}}$ deteriorates faster than $\sigma$, and a higher $\mathrm{Al}$ ion content always deteriorates slower than a lower $\mathrm{Al}$ ion content.

\section{References}

[1] T. Sueyoshi, H. Naono and M. Amemiya, IEEE Trans. Magn., $M A G-20(1984) 42$.

[2] Y. Yamamoto, K. Sumiya, A. Miyake, M. Kishimoto and T. Taniguchi, IEEE Trans. Magn., MAG-26 (1990) 2098.

[3] T. Miyahara and K. Kawakami, IEEE Trans, Magn, MAG-23 (1987) 2877.

[4] M. Kishimoto, S. Kitahata and M. Amemiyia, IEEE Trans. Magn., MAG-22 (1986) 732.

[5] N. Mizutani et al. (eds.), Proc. 3rd IUMRS Int. Conf. on Advanced Materials, Tokyo, Japan, 1993, in Aduanced Materials '93, Trans. Mater. Res. Soc. Jpn., Vol. 14A, Elsevier, Amsterdam, 1994, p. 45. 